\title{
Effect of resealing on microleakage of resin composite restorations in relationship to margin design and composite type
}

Sibel A. Antonson ${ }^{1}$

A. Ruya Yazici²

Zeynep Okte ${ }^{3}$

Patricia Villalta ${ }^{4}$

Donald E. Antonson ${ }^{1}$

Patrick C. Hardigan ${ }^{5}$

\section{ABSTRACT}

Objective: To determine the relationship between margin preparation design and resin-composite type on microleakage with or without re-application of surface-penetrating sealant.

Methods: Class-I resin-composite restorations were completed for 128 extracted human molars. Half of the margins were beveled, the other half, butt-joint. Half of each group was restored with FiltekSupreme (FS), the other half with Esthet-X (EX) using their respective adhesive systems. Margins were etched and sealed with a surface-penetrating sealant, Fortify. The samples were stored in water $24 \mathrm{~h}$, and thermocycled $\left(5,000\right.$ cycles, $\left.5^{\circ} \mathrm{C}-55^{\circ} \mathrm{C}\right)$. Then, samples were abraded using a toothbrush machine 16,000 strokes). Half of the restorations from each sealant group $(n=16)$ were resealed, and the other half had no further treatment. Thermocycling and tooth brushing were repeated. The samples were sealed with nail polish, immersed in methylene-blue for $8 \mathrm{~h}$, sectioned, and magnified digital photographs were taken. Three examiners assessed dye penetration. A 2×2×2 multi-layered Chi-Square analysis, using Cochran-Mantel-Haenszel test was conducted for statistical analysis.

Results: No difference was observed between sealed and resealed FS and EX restorations with butt-joint margins. In beveled margins, resealing caused significantly less microleakage $(P<.01)$. No differences were found between restorations either sealed or resealed with bevel margins. In butt-joint margins, at the leakage level deeper than $2 / 3$ of the preparation depth, resealed FS showed less microleakage than EX resealed restorations $(P<.01)$.

Conclusion: Resealing reduced microleakage in bevel margins, however, in butt-joint margins resealing did not affect the leakage. A significant statistical relationship exists between and within resealing, margin preparation design, type of composite, and microleakage. (Eur J Dent 2012;6:389-395)

Key words: Resin-composite margin design; bevel; butt-joint; surface penetrating sealant; microleakage

1 Department of Restorative Dentistry, University at Buffalo State University of New York School of Dental Medicine, Buffalo, NY, USA

2 Hacettepe University, Faculty of Dentistry, Department of Conservative Dentistry, Ankara, TURKIYE

3 Ankara University, Faculty of Dentistry, Department of Pediatric Dentistry, Ankara, TURKIYE

4 Nova Southeastern University, Department of Pediatric Dentistry, Fort Lauderdale, FL, USA
Nova Southeastern University, Health Professions Division, Fort Lauderdale, FL, USA

- Corresponding author: Dr. Sibel A. Antonson University at Buffalo State University of New York, School of Dental Medicine, Department of Restorative Dentistry, 215 Squire Hall, Buffalo, NY, 14214 USA

Tel: +1 7168292862

Email: sibeladabuffalo.edu 


\section{INTRODUCTION}

The use of resin composite restorations is increasing due to the benefits derived from adhesive bonding to tooth structure and their esthetic qualities. Despite their wide use, resin composites still present relevant drawbacks such as polymerization shrinkage, which remains a major concern in operative dentistry. ${ }^{1}$ Shrinkage stress causes a disruption between the restoration and the preparation wall or a cohesive failure in the restoration or surrounding tooth, which might cause marginal failure of the restoration. Failures may result from marginal leakage that creates the potential for secondary caries, post-operative sensitivity, marginal staining and, if left untreated, advance to pulpal pathology. ${ }^{2}$ The stress generated during polymerization of resin composite is influenced by several factors related to the material, technique, cavity preparation and their respective interactions. ${ }^{3}$ Therefore, numerous strategies have been proposed such as a layering technique, the use of a flexible lining material or sealing the restoration margins.

Retention and marginal seal might also be improved by beveling enamel margins. Beveling increases favorable end-on etching of enamel prisms and increases the surface area for resin bonding. ${ }^{4}$ Even though there might be advantages, bevels are not usually placed on the occlusal surfaces of posterior teeth or other areas of heavy contact because a conventional preparation design already produces end-on etching of the enamel rods by virtue of the enamel rod direction on occlusal surfaces. Therefore, a beveled preparation design is rarely used for posterior composite restorations. ${ }^{4}$ On the other hand, there are controversial results regarding this issue. In some studies, it has been demonstrated that beveled margins exhibit less microleakage $e^{5,6}$ and reduce marginal tooth fracture ${ }^{7}$, while some investigations found no difference between beveled and butt-joint ended margins. ${ }^{8,9}$ It has been proposed that butt-joint margins of well-bonded restorations wear more slowly and create a meniscus appearance against the enamel. However, as beveled composite margins wear, thinner edges of material are produced that are more prone to fracture. ${ }^{10}$

The use of surface penetrating sealants is another procedure to improve marginal seal and the longevity of the restorations. These materials have characteristics of wettability and viscosity that can penetrate in the microcracks formed on the surface and to the debonded interface by capillary action. ${ }^{11,12}$ It has been reported that the degree of penetration of the surface sealant and its effectiveness in increasing the marginal integrity depends on the material's viscosity and the ability to wet the surfaces. ${ }^{13,14}$ Previous studies have shown that surface penetrating sealants were effective in reducing marginal leakage. ${ }^{11-15}$ However, re-application of sealant might be needed because of the property of this material to wear when exposed to thermal and abrasive oral conditions, consequently losing its effectiveness.

There are advances in resin composite technology that affect their properties, their interaction with dental tissues and marginal integrity. One of the most important discoveries in the last few years is the application of nanotechnology to resin composites. By using nanotechnology, manufacturers can provide highly filled composites with lower shrinkage, higher wear resistance and better polishability and gloss. ${ }^{16-18}$ However, new classification of composites may result with different microleakage behavior.

To the extent of the authors' knowledge, no information is available in the literature regarding the relationship of resealing and the design of the preparation margin's effect on microleakage of resin restorations. Therefore, the aim of this in vitro study was to evaluate the effect of resealing on microleakage of Class I resin composite restorations in relationship to preparation margin design and resin composite type. The null hypothesis was that the resealing effect on microleakage would not differ according to the margin preparation design and different resin composite type.

\section{MATERIALS AND METHODS}

One hundred and twenty eight extracted intact human molar teeth, which had been stored in deionized water with $0.2 \%$ sodium azide no longer than one month, was selected for the study. Standardized Class I preparations were completed using a diamond cylinder bur (Diatech, Swiss Dental Instruments, Heerbrugg, Switzerland) in a water-cooled high-speed handpiece. The preparation size was standardized in a mesio-distal direction to a length of $4 \mathrm{~mm}$ and a width in the bucco-lingual direction of $2 \mathrm{~mm}$. The depth was set at $2 \mathrm{~mm}$. A new bur was used with every five specimens.

Preparations were then randomly assigned into two groups according to the margin preparation design; half of them were finished with a butt-joint, half of them were beveled with a fine diamond bur (\#132F, Brasseler, Savannah, GA, USA). Then the prepared teeth were randomly divided into two groups: 
Filtek Supreme (FS): Preparations were etched with 37.5\% phosphoric acid (Scotchbond Etchant, $3 \mathrm{M}$ ESPE, St Paul, MN, USA) for 30 seconds in enamel and 15 seconds in dentin. After the preparations were thoroughly rinsed with water for 15 seconds, they were air dried gently approximately $10 \mathrm{~cm}$ away from the preparation surface for 5 seconds, avoiding complete desiccation. Two consecutive coats of Adper Single Bond (3M Dental Products, St Paul, MN, USAl were applied to the entire preparations, followed by gentle air drying to remove excess solvent, and then light cured with a quartz-tungsten-halogen light (Optilux 501, Kerr, Orange, CA, USA) for 20 seconds. Before use, the curing light was tested with a curing radiometer and found to have an output of at least $475 \mathrm{~mW} /$ $\mathrm{cm}^{2}$, which was considered adequate. The preparations were then restored with FS in bulk and light-cured with a halogen light for 40 seconds.

Esthet-X (EX): Preparations were etched with 37.5\% phosphoric acid (Scotchbond Etchant, 3M ESPE, St Paul, MN, USA) for 30 seconds on enamel and 15 seconds on dentin. After the preparations were thoroughly rinsed with water for 15 seconds, they were gently air dried approximately $10 \mathrm{~cm}$ away from the preparation surface for five seconds, avoiding complete desiccation. Prime \& Bond NT (Dentsply Caulk, Milford, DE, USA) was applied to thoroughly wet all the tooth surfaces. After the surface remained wet for 20 seconds, excess solvent was removed by gently drying for at least 5 seconds. Prime \& Bond NT was cured for 10 seconds using the same curing light. The second coat was applied following the same procedure. The preparations were then restored with EX in bulk and light-cured with a halogen light for 40 seconds.
After 24 hours storage in water at $37^{\circ} \mathrm{C}$, all samples were finished with 30 -blade carbide burs (\#H274UF, Brasseler, Savannah, GA, USA) and polished with abrasive impregnated brushes (Astrobrush, Ivoclar Vivadent, Amherst, NY, USA). The margins of the restorations were etched with 37.5 $\%$ phosphoric acid for 15 seconds, subsequently rinsed for 20 seconds with water and air dried for five seconds. A thin coat of surface penetrating sealant, Fortify (Bisco, Schaumburg, IL, USA) was applied and air thinned by blowing a gentle stream of air to ensure an even distribution. Then the surface was polymerized for 10 seconds. The materials used in this study are displayed in Table 1.

After the specimens were stored in distilled water for 24 hours, all specimens were subjected to thermocycling $\left(5,000\right.$ cycles at $5^{\circ} \mathrm{C}$ and $55^{\circ} \mathrm{C}$ with a 60-second dwell timel. They were then treated with a simulated tooth brushing technique using a toothbrush device (V.8 Cross Brushing Machine, Bodine Electric Co., Chicago, IL, USA). The brushing heads were fitted with nylon bristles (Oral B, Procter \&Gamble, Cincinatti, Ohio, USA). Care was taken to ensure that bristles were perpendicular to the surface of each sample and touched the surface evenly. A 50:50 (w/w) slurry of toothpaste (Crest, Procter \&Gamble) and deionized water was used as abrasive medium. Each surface was brushed 6,000 times using a brush head contact force of 300 grams.

Following the abrasion, the samples were further divided into two sub-groups. While half of each sealant group ( $n=16 /$ group) was resealed with Fortify, the other half had no treatment. Thermocycling and tooth brushing were repeated for all of the samples following the same protocol described above. After the apices of all root sur-

Table 1. Materials used in this study

\begin{tabular}{|c|c|}
\hline Materials & Composition \\
\hline Filtek Supreme (3M ESPE St. Paul, MN, USA) & Filler: Silica/zirconia filler with a mean particle size of $0.6 \mu \mathrm{m}$ \\
\hline Batch \#3BF & Polymeric matrix: Bis-GMA, Bis-EMA, UDMA, TEGDMA \\
\hline \multirow{2}{*}{$\begin{array}{l}\text { Esthet-X (Dentsply Caulk, Milford, DE, USA) } \\
\text { Batch \# } 0611221\end{array}$} & $\begin{array}{l}\text { Filler: Barium fluoro alumino borosilicate glass and nano-sized silicon dioxide } \\
\text { particles }\end{array}$ \\
\hline & Polymeric matrix: Bis-GMA, TEGDMA, Bis-EMA \\
\hline \multirow[b]{2}{*}{$\begin{array}{l}\text { Adper Single Bond (3M ESPE St. Paul, MN, USA) } \\
\text { Batch \# } 20051007\end{array}$} & Etchant: Scotchbond acid-37\% phosphoric acid \\
\hline & $\begin{array}{l}\text { Bis-GMA, HEMA, co-polymer of acrylic/itaconic acids, diurethane dimethacrylate, } \\
\text { glyceroldimethacrylate, water and ethanol }\end{array}$ \\
\hline $\begin{array}{l}\text { Prime \& Bond NT (Dentsply Caulk, Milford, DE, USA) } \\
\text { Batch \# } 0809001941\end{array}$ & $\begin{array}{l}\text { Di- and Trimethacrylate resins, PENTA, nanofillers-amorphous silicon dioxide, } \\
\text { photoinitiators stabilizers, cetylamine hydrofluoride, acetone }\end{array}$ \\
\hline $\begin{array}{l}\text { Fortify (BISCO, Schaumburg, IL, USA) } \\
\text { Batch \# G- } 9300 \text { F, } 0300004571\end{array}$ & UDMA, BisEMA \\
\hline \multicolumn{2}{|c|}{$\begin{array}{l}\text { Abbreviations: Bis-GMA: bis-phenol A diglycidylmethacrylate; HEMA: 2-hydroxyethyl methacrylate; UDMA: Urethane dimethacrylate; } \\
\text { PENTA: Dipentaerythritol pentacrylate monophosphate; BisEMA: Bisphenol A ethoxylated dimethacrylate; TEGDMA: Triethylene glycol } \\
\text { dimethacrylate }\end{array}$} \\
\hline
\end{tabular}


faces were occluded with composite resin, the tooth surfaces were coated with two layers of nail varnish up to $2 \mathrm{~mm}$ from the restoration margins. The teeth were immersed in a $5 \%$ methylene blue for 8 hours at $37^{\circ} \mathrm{C}$ and rinsed until all dye was removed from the surface. The specimens were then sectioned through the center of restorations in a mesio-distal direction using a low-speed diamond blade saw (Isomet, Buehler Ltd, Lake Bluff, IL, USA). Some of the samples were unscorable due to the complications during sectioning, and thus eliminated (Table 2). The dye penetration was assessed with three independent calibrated examiners using a light microscope under x40 magnification. Cohen's kappa, calculated to determine inter-and intraexaminer reproducibility was 0.99 and 0.95 , respectively. The images were captured by a digital camera connected to computer using image analyzer software.

The dye penetration was scored as follows:

$0=$ no penetration

$1=$ dye penetration up to $1 / 3$ of the restoration depth

$2=$ dye penetration up to $2 / 3$ of the restoration depth,

$3=$ dye penetration to the pulpal wall

A 2x2x2 multi-layered Chi-Square analysis using the Cochran-Mantel-Haenszel test was conducted to see if microleakage was independent of groups ( $\alpha=.01)$.

\section{RESULTS}

The dye penetration scores are displayed in Table 2. Resealing did not cause any significant difference in microleakage scores of FS and EX restorations with butt-joint margins. In bevel margins, resealing caused significantly less microleakage for both of the groups $(P<.01)$.

In EX sealed restorations, no difference was found between beveled and butt-joint prepared restorations $(P>$.01). In EX resealed restorations, beveled restorations demonstrated more frequent deep microleakage. While no difference was ob- served between bevel and butt-joint margins in FS resealed restorations ( $P>$.01), margins leaked deeper in beveled restorations in sealed FS restorations $(P<.01)$.

When comparing the two resin composites, no statistically significant differences were observed between restorations either sealed or resealed with bevel margins ( $P>$.01). In butt-joint margins, resealed FS restorations showed less microleakage than EX resealed restorations at scores 2 $(P<.01)$.

A significant statistical relationship exists between and within resealing, margin preparation design, type of composite, and microleakage $(P<.01)$.

\section{DISCUSSION}

This in vitro study evaluated the relationship between the margin preparation design and type of composite on microleakage with or without reapplication of surface-penetrating sealant. A number of in vitro studies have been conducted that compare the microleakage behavior of beveled and unbeveled restorations. However, the results have not been consistent. In some studies it has been demonstrated that beveled margins exhibit less microleakage than those possessing a standard butt-joint. ${ }^{19-21}$ These studies attributed the results to the increased surface area of the cut enamel caused by beveling, thereby making it more difficult for fluids to penetrate in the restoration-tooth interface. When the enamel margins are beveled to produce transverse sections of enamel prisms, the bond strength between enamel and resin increases. ${ }^{22.23}$ Furthermore, because the beveled region can be firmly bonded to the resin, the enamel margins are reinforced, resulting in an increased resistance of this region to polymerization shrinkage. ${ }^{24}$

On the other hand, according to Bagheri and Ghavamnasiri ${ }^{25}$ who compared the marginal leakage of hybrid and microfilled composite resin in Class $\mathrm{V}$ restorations with and without an enamel

Table 2. Dye penetration scores.

\begin{tabular}{|c|c|c|c|c|c|c|c|c|}
\hline \multirow{3}{*}{ Score } & \multicolumn{4}{|c|}{ Bevel } & \multicolumn{4}{|c|}{ Butt-Joint } \\
\hline & \multicolumn{2}{|c|}{ Filtek Supreme } & \multicolumn{2}{|c|}{ Esthet-X } & \multicolumn{2}{|c|}{ Filtek Supreme } & \multicolumn{2}{|c|}{ Esthet-X } \\
\hline & Seal & Reseal & Seal & Reseal & Seal & Reseal & Seal & Reseal \\
\hline 0 & 6 & 14 & 7 & 13 & 9 & 11 & 7 & 8 \\
\hline 1 & 1 & 1 & 1 & 2 & 5 & 4 & 4 & 1 \\
\hline 2 & 3 & 0 & 5 & 1 & 1 & 1 & 1 & 7 \\
\hline 3 & 5 & 1 & 2 & 0 & 0 & 0 & 2 & 0 \\
\hline Total & 15 & 16 & 15 & 16 & 15 & 16 & 14 & 16 \\
\hline
\end{tabular}


bevel, no significant difference between the two types of composites and two types of enamel margins with respect to microleakage were noted. They reported that an enamel bevel in a Class $V$ preparation had no effect on the reduction of marginal leakage using either hybrid or microfilled composite resin. Similar to this result, Santini et $\mathrm{al}^{26}$ evaluated microleakage around Class $\mathrm{V}$ resinbased composite restorations in box-shaped preparations with and without marginal bevels, bonded with self-etch and etch-and-rinse adhesives. They found no significant difference in leakage between beveled and unbeveled groups. Ameri et al ${ }^{27}$ evaluated the influence of mechanical loading and thermocycling on microleakage of Class $V$ resin-based composite restorations with and without enamel bevels. They found that the non-beveled preparations in this study had significantly less microleakage than the bevel specimens. No benefit was derived from placing an enamel cavosurface bevel on the occlusal margin of standardized Class $V$ composite restorations located at the cementoenamel junction.

In a three year clinical study, ${ }^{28}$ effects of enamel beveling on the clinical performance of Class $V$ composite restorations was evaluated. At the end of the study, it was claimed that enamel beveling did not significantly affect the clinical performance of restorations. Similar findings were observed in most of the clinical trials. ${ }^{29-32}$ In a meta-analytic study $^{33}$ that had assessed the influencing factors on retention loss and marginal discoloration of cervical composite restorations, it was concluded that the additional enamel beveling can be omitted as beveling of the enamel had no significant influence the clinical performance of the restorations.

In the present study, surface penetrating sealant was applied in both types of preparation margin designs, and therefore the results cannot be compared directly with the mentioned previous studies. In the FS resealed restorations, cavity preparation design, bevel vs. butt-joint margins did not affect the leakage scores. However in onetime sealed restorations, beveling caused more leakage in Score 2. On the other hand, no difference was found between bevel and butt-joint margins in EX sealed restorations. However, butt-joint margins showed more leakage in Score 2 in EX resealed restorations. There were no differences between different preparation margin designs in leakage Score of 1 . The reason why there was no difference between beveled and butt-joint margins in most of the restorations might be related with the application of surface sealant. In many stud- ies, surface penetrating sealants were found to be effective in preventing microleakage. ${ }^{11-15}$

In a clinical study by Dickinson and Leinfelder ${ }^{34}$ assessing the long-term effect of a surface penetrating sealant, it was observed that surface penetrating sealants not only were effective in reducing wear rates, but also were effective in improving marginal integrity. They also concluded that the surface penetrating sealant's effectiveness could be enhanced if the material was reapplied biannually. Therefore, this current study investigated the effect of resealing on microleakage. Assuming that these sealing agents might lack sufficient abrasion resistance and might be easily lost, the specimens were subjected to tooth brushing simulation. This procedure was repeated after resealing the restorations. After repeating the simulated abrasion, it was found that the sealant should be reapplied for the preparations with a bevel as sealed restorations leaked more than resealed restorations. This finding could be attributed to the thinner edges of material in beveled restorations. As the resin composite margins and surface sealants wear, these areas might become more prone to marginal openings, therefore microleakage. However, re-application of surface sealant did not change the leakage scores in restorations with butt-joint margins. Sealed restorations with buttjoint margins might have been resistant to wear more than restorations with a beveled margin. It has been reported that surface penetrating sealants could also decrease wear on the occlusal surface of posterior resin composite restorations. ${ }^{34,35}$

Additionally, the relationship between different types of resin composites with different margin design and re-application of sealant was evaluated. Due to the composition of the materials used in this study, it might have been expected that the nanofilled resin composite, FS, might have shown less leakage compared to the microhybrid composite, EX. However the difference between two types of resin composites was only found in buttjoint resealed restorations; where FS restorations showed less leakage in score 2. For the rest of the combinations, both resin composites showed similar leakage scores. This might be due to the similar polymerization shrinkage value of the two resin composites and the similar filler content volume. In previous studies, no significant differences in leakage scores were found between the nanofilled or the microhybrid resin composite materials. ${ }^{36-38}$

As a result of the current study, it can be stated that the resealing effect on microleakage would differ according to the margin preparation de- 
sign (bevel or butt-joint) and to the different resin composite type. Therefore, the null hypothesis has to be rejected. Beveled cavity preparations might need frequent resealing procedures in order to avoid microleakage. Although laboratory data provides less reliable evidence than in vivo trials, these kinds of microleakage studies can be used as a part of an in vitro screening of new techniques or materials. Further clinical studies should be conducted to determine whether the beveling and resealing of restorations would provide any clinical benefit to longevity and reduced marginal staining around restorations.

\section{REFERENCES}

1. St Georges AJ, Wilder AD Jr, Perdigão J, Swift EJ Jr. Microleakage of Class $V$ composites using different placement and curing techniques: an in vitro study. Am J Dent 2002;15:244-247.

2. Van Meerbeek B, Perdigão J, Lambrechts $P$, Vanherle G. The clinical performance of adhesives. J Dent 1998;26:1-20.

3. Peutzfeldt A, Asmussen E. Determinants of in vitro gap formation of resin composites. J Dent 2004;32:109-115.

4. Roberson TM, Heymann HO, Ritter AV. Introduction to composite restorations. In: Roberson TM, Heymann HO, Swift J E (eds). Sturdevant's Art and Science of Operative Dentistry. St. Louis: Mosby, 2002:489-490.

5. Eriksen HM, Buonocore MG. Marginal leakage with different composite restorative materials in vitro. Effect of cavity design. J Oral Rehabil 1976;3:315-322.

6. Welk DA, Laswell HR. Rationale for designing cavity preparations in light of current knowledge and technology. Dent Clin North Am 1976;20:231.

7. Oilo G, Jorgensen KD. Effect of bevelling on the occurrence of fractures in the enamel surrounding composite resin fillings. J Oral Rehabil 1977;4:305-309.

8. Eliasson ST, Hill GL. Cavosurface design and marginal leakage of composite resin restorations. Oper Dent 1977;2:5558.

9. Retief DH, Woods E, Jamison HC. Effect of cavosurface treatment on marginal leakage in Class $\mathrm{V}$ composite resin restorations. J Prosthet Dent 1982;47:496-501.

10. Bayne SC, Thompson JY, Taylor DF. Dental Materials. In: Roberson TM, Heymann HO, Swift J EJ (eds). Sturdevant's Art and Science of Operative Dentistry. St. Louis: Mosby, 2002:207.

11. dos Santos PH, Pavan S, Assunção WG, Consani S, CorrerSobrinho L, Sinhoreti MA. Influence of surface sealants on microleakage of composite resin restorations. J Dent Child 2008;75:24-28.
12. Ramos RP, Chimello DT, Chinelatti MA, Palma Dibb RG, Mondelli J. Effect of three surface sealants on marginal sealing of class V composite resin restorations. Oper Dent 2000;25:448-453.

13. Ramos RP, Chinelatti MA, Chimello DT, Dibb RG. Assessing microleakage in resin composite restorations rebonded with a surface sealant and three low-viscosity resin systems. Quintessence Int 2002;33:450-456.

14. Reid JS, Saunders WP, Chen YY. The effect of bonding agent and fissure sealant on microleakage of composite resin restorations. Quintessence Int 1991;22:295-298.

15. Silva Santana SV, Bombana AC, Flório FM, Basting RT. Effect of surface sealants on marginal microleakage in Class V resin composite restorations $J$ Esthet Rest Dent 2009;21:397404.

16. Mitra SB, Wu D, Holmes BN. An application of nanotechnology in advanced dental materials. J Am Dent Assoc 2003;134:1382-1390.

17. Senawongse $P$, Pongprueksa P. Surface roughness of nanofill and nanohybrid resin composites after polishing and brushing. $J$ Esthet Rest Dent 2007;19:265-273.

18. Topcu F, Sahinkesen G, Yamanel K, Erdemir U, Oktay EA, Ersahan S. Influence of different drinks on colour stability of dental resin composites. Eur J Dent 2009;3:50-56.

19. Schmidlin PR, Wolleb K, Imfeld T, Gygax M, Lussi A. Influence of beveling and ultrasound application on marginal adaptation of box-only Class II (slot) resin composite restorations. Oper Dent 2007;32:291-297.

20. Swanson TK, Feigal RJ, Tantbirojn D, Hodges JS. Effect of adhesive systems and bevel on enamel margin integrity in primary and permanent teeth. Pediatr Dent 2008;30:134140.

21. Hall LH, Cochran MA, Swartz ML. Class 5 composite resin restorations: margin configurations and the distance from the CEJ. Oper Dent 1993;18:246-250.

22. Crawford PJM, Whittaker DK, Owen GM. The influence of enamel prism orientation on leakage of resin bonded restorations. J Oral Rehabil 1987;14:283-289.

23. Munechika T, Suzuki K, Nishiyama M, Ohashi M, Horie K. A comparison of the tensile bond strengths of composite resin to longitudinal and transverse sections of enamel prisms in human teeth. J Dent Res 1984;63:1079-1082.

24. Han L, Okamoto A, Iwaku M. The effects of various clinical factors on marginal enamel micro-cracks produced around composite restoration. Dent Mater J 1992;11:26-37.

25. Bagheri M, Ghavamnasiri M. Effect of cavosurface margin configuration of Class $V$ cavity preparations on microleakage of composite resin restorations. J Comtemp Dent Prac 2008;9:122-129 
26. Santini A, Ivanovic V, Ibbetson R, Milia E. Influence of marginal bevels on microleakage around Class $V$ cavities bonded with seven self-etching agents. Am J Dent 2004;17:257261.

27. Ameri H, Ghavamnasiri M, Abdoli E. Effects of load cycling on the microleakage of beveled and nonbeveled occlusal margins in class $\mathrm{V}$ resin-based composite restorations. $J$ Contemp Dent Pract 2010;11:25-32.

28. Baratieri LN, Canabarro S, Lopes GC, Ritter AV. Effect of resin viscosity and enamel beveling on the clinical performance of Class $V$ composite restorations: three-year results. Oper Dent 2003;28:482-487.

29. Coelho-de-Souza FH, Klein-Júnior CA, Camargo JC, Beskow T, Balestrin MD, Demarco FF. Double-blind randomized clinical trial of posterior composite restorations with or without bevel: 6-month follow-up. J Contemp Dent Pract 2010;11:1-8.

30. Perdigão J, Anauate-Netto C, Carmo AR, Lewgoy HR, Cordeiro HJ, Dutra-Corrêa M, Castilhos N, Amore R. Influence of acid etching and enamel beveling on the 6-month clinical performance of a self-etch dentin adhesive. Compend Contin Educ Dent 2004;25:33-34.

31. Heintze SD, Ruffieux C, Rousson V. Clinical performance of cervical restorations--a meta-analysis. Dent Mater 2010;26:993-1000.

32. Wilson NHF, Wilson MA, Wastell DG, Smith GA. Performance of Occlusion in butt-joint and beveled-edged preparations: Five-year results. Dent Mater 1991;7:92-98

33. Isenberg BP, Leinfelder KF. Efficacy of beveling posterior composite resin preparations. J Esthet Dent 1990;2:70-73.

34. Dickinson GL, Leinfelder KF. Assessing the long-term effect of a surface penetrating sealant. $J$ Am Dent Assoc 1993;124:68-72.

35. Dickinson GL, Leinfelder KF, Mazer RB, Russell CM Effect of surface penetrating sealant on wear rate of posterior composite resins. J Am Dent Assoc 1990;121:251-255.

36. Hardan LS, Amm EW, Ghayad A, Ghosn C, Khraisat A. Effect of different modes of light curing and resin composites on microleakage of Class II restorations--Part II. Odontostomatol Trop 2009;32:29-37.

37. Sadeghi M. Influence of flowable materials on microleakage of nanofilled and hybrid Class II composite restorations with LED and QTH LCUs. Ind J Dent Res 2009;20:159-163.

38. Yamazaki PC, Bedran-Russo AK, Pereira PN, Swift EJ Jr. Microleakage evaluation of a new low-shrinkage composite restorative material. Oper Dent 2006;31:670-676. 